\title{
EDITORIAL
}

\section{In This Issue: Research in the Community and Clinic}

\author{
William R. Pbillips, MD, MPH, Senior Associate Editor \\ Ann Fam Med 2004;2:98-100. DOI: 10.1370/afm.129.
}

$\mathrm{T}$ The Annals of Family Medicine is growing in number of pages, number of readers, and breadth of content. This issue includes research and reflection on illness as it occurs in our communities and our practices and on the roles primary care can play in easing those burdens.

Community-oriented primary care (COPC) is a theoretical cornerstone in the foundation of primary care. In this issue, Plescia and Groblewski ${ }^{1}$ describe an exemplary COPC project developing interventions for physical activity and healthy diet to reduce cardiovascular disease and diabetes. Using data collected by trained community interviewers visiting 386 randomly selected households, they designed community- and clinic-based interventions tailored to meet the needs of the patients and community they serve.

Williams discusses the promises and problems of COPC in his insightful editorial commenting on this project. ${ }^{2}$ Plescia and Groblewski make the attractive COPC concept come alive with their description of the partnership they created in their community. Williams observes, however, that examples of practical programs are still rare in the literature on COPC. Demonstrations of effectiveness are rarer still and present one of the greatest challenges to the integration of community and personal health services in the fragmented, competitive, US system.

Childhood asthma is a major problem, increasing in industrialized countries, affecting lives, and consuming resources. Community-based studies of the natural history of such common problems can inform primary care practice in ways that cross-sectional data from referral centers simply cannot. WinklerPrins and colleagues ${ }^{3}$ in the Netherlands report a large, prospective study of a birth cohort of 581 children. They screened all children with bronchial hyperresponsiveness (BHR) tests and respiratory symptom questionnaires and then observed them for 10 years for respiratory tract problems. The investigators found that early diagnosis of asthma and abnormal BHR were both poor predictors of subsequent respiratory tract disease. The symptom questionnaire was more successful at predicting asthma in young people and may be useful in practice. One half of the children identified as asthmatic at the outset had no subsequent physician visits for asthma in more than 10 years.

The patterns of care for hepatitis $\mathrm{C}$ patients are described by Rocca and colleagues ${ }^{4}$ in Olmsted County, Minn, where the comprehensive record system allows tracking of patient history across the county and over the years. They documented rates of infection, diagnosis, treatment discussion, and referral. By studying each step in the process of care, they identified opportunities to increase the proportion of infected individuals who are provided options for treatment, particularly among those in emergency departments and chemical dependency programs.

Physician errors are the subject of a survey by Elder, Vonder Meulen, and Cassedy. ${ }^{5}$ They report on the errors family physicians describe in their day-to-day practices and the potential for harm to patients. The range of self-reported error rates and the variety of opinions about what constitutes harm to patients call out for further study. Patient safety is an area of prime interest to practitioners, patients, and policy makers, and we encourage all to contribute to a vigorous online TRACK discussion of this topic.

Advances in cancer genetics create an active interface between patient care and new technology in the identification of patients with a family history of inheritable cancer risk. Gramling and team, ${ }^{6}$ who surveyed community-based family physicians in Massachusetts, found that most believed screening was important but doubted their own professional effectiveness. We should expect that advances in biomedical science might require advances in education, clinical skills, and systems of care.

Analyzing population-based data from US National Health and Nutrition Examination Surveys (NHANES), Mainous and team studied mortality and elevated levels of serum transferrin saturation, a measure of iron overload. In the first study, ${ }_{1}^{7}$ they found elevated levels were associated with death from all causes. In the accompa- 
nying study, ${ }_{1}^{8}$ they further found that in persons with elevated levels of serum transferrin saturation, eating large amounts of red meat and other iron-containing foods was associated with increased death rates.

Reducing the rates of neonatal morbidity and mortality are major goals in our practices and our communities, and low birth weight is the major cause of these tragic outcomes. In the first prospective study of such factors, Keeley and colleagues ${ }^{9}$ report interesting associations between parental attitudes toward pregnancy and low birth weight. Mothers who report they are unhappy with the present pregnancy are more likely to give birth to low birth weight babies. The investigators found a stronger and more intriguing association between infant low birth weight and mothers' reports that the father was happier than they were about the pregnancy. More study of more patients will be required to follow up on this finding. Most prevention strategies target high-risk pregnancies, but these findings among average risk mothers suggest opportunities for new ways to identify and intervene in pregnancies to reduce complications.

Communities and clinics rely upon high-quality primary care and the professionals that provide it. Organizations must sustain the clinicians that provide the care, yet many physicians express frustration with the systems in which they work. Gask ${ }^{10}$ interviewed a group of family physicians in one group model health maintenance organization in the northwestern United States about their opinions about working in the organization and practicing with their primary care teams. Her thoughtful analysis identified 3 themes of concern: powerlessness, control, and complexity. She calls for health care organizations to restore a sense of professional autonomy, to increase control over the work environment, and to value more highly the skills in managing clinical and organizational complexity that are particular to family practice.

Also in this issue, the US Preventive Services Task Force (USPSTF) publishes its new recommendation statement on screening for family and intimate partner violence. ${ }^{11}$ The USPSTF found no direct evidence that screening for family and intimate partner violence leads to decreased disability or premature death. Evidence to support this USPSTF statement is provided by Nelson, Nygren, and Klein ${ }^{12}$ in their systematic review on screening children for family violence. The evidence report provides further details in the appendices in the online Annals.

In another systematic review, Park et $\mathrm{al}^{13}$ assessed the effectiveness of involving partners in programs to help patients quit smoking. Despite the intuitive appeal of including partners, they found no evidence of effect in clinical trials, even using several definitions of partner. Trends in the data suggest further studies that might improve our effectiveness in reducing the enormous personal and public health problem of tobacco use.
The essay by Rosenblatt ${ }^{14}$ shares a view from both ends of the microscope: the objective specimen and the subjective eyepiece. His personal experience of cancer-and of cancer care in an academic medical center-magnify the fine structure of illness, care, and healing. The image leaves much to be filled in by the personal physician.

\section{THE FUTURE OF FAMILY MEDICINE SUPPLEMENT}

We are also pleased to present the first Annals supplement, the report of the Future of Family Medicine Project. ${ }^{15}$ Begun with a goal "to transform and renew the discipline of family medicine to meet the needs of patients in a changing health care environment," this project was conducted by 7 family medicine organizations. It engaged a large group of concerned individuals in gathering information, identifying challenges and opportunities, and presenting a plan for moving forward.

The main findings are presented in a report and are available both online ${ }^{16}$ (http://www.annfammed.org/ cgi/content/2/suppl_1/S3) and in a print supplement. ${ }^{14}$ More details are available in the reports of 5 task forces that are published online (http://www.annfammed.org). To quickly understand the essence of the report, we recommend reading the abstract at the beginning and the 10 recommendations at the end of the report.

The report presents a starting point for action. It will be useful only if it becomes a living blueprint that evolves through interaction with those who care about the potential of family medicine and its partners to improve health and health care. This job is not just for family physicians, it is for everyone who is willing to work for personalized, integrated, high-quality health care in a sustainable, equitable health care system. We encourage everyone with these concerns to use these documents as a starting point for discussion and action. We particularly invite comments from readers around the world and both inside and outside the health care professions.

\section{INDEXING BY INDEX MEDICUS AND MEDLINE}

We are delighted to announce that the National Library of Medicine (NLM) has selected the Annals of Family Medicine for inclusion in Index Medicus. Inclusion in Index Medicus is a mark of recognition of the quality of a biomedical journal. The NLM bases selection on peer review of content, quality, and scope. Indexing is restricted to journals that meet the current needs of practitioners, investigators, educators, and policy makers.

Indexing in MEDLARS and MEDLINE databases 
will enable readers to search and retrieve all Annals articles, including all past issues. While the full content of the Annals has always been immediately available free online to readers worldwide, this indexing makes the titles and abstracts searchable with the full power of PubMed and related programs.

Indexing is also formal recognition of the contributions of many people who are part of the Annals community. This includes authors, who submit excellent quality manuscripts; reviewers, who donate time and expertise; and readers, who provide thoughtful commentary in the TRACK online discussion. In addition, the publisher produces a superb journal in print and online, and our sponsoring organizations support the cost of this new enterprise and guarantee the editorial independence needed to bring these resources together into a professional, innovative, peer-reviewed journal. We are grateful to everyone who has contributed to reaching this milestone, and we appreciate the privilege of serving you.

Full-text and PDF of all articles are freely available online. We encourage readers to share their experiences and views on these topics by posting comments to the Annals TRACK discussions at http://www.annfammed.org.

To read or post commentaries in response to this article, see it online at http://www.annfammed.org/cgi/content/full/2/2/98.

\section{References}

1. Plescia M, Groblewski M. A community-oriented primary care demonstration project: refining interventions for cardiovascular disease and diabetes. Ann Fam Med. 2004;2:103-109.

2. Williams RL. Motherhood, apple pie, and COPC. Ann Fam Med. 2004;2:100-102.
3. WinklerPrins $\mathrm{V}$, van den Nieuwenhof $\mathrm{L}$, van den Hoogen $\mathrm{H}$, Bor $\mathrm{H}$ van Weel C. The natural history of asthma in a primary care cohort. Ann Fam Med. 2004;2:110-115.

4. Rocca LG, Yawn BP, Wollan P, Kim WR. Management of patients with hepatitis $C$ in a community population: diagnosis, discussions, and decisions to treat. Ann Fam Med. 2004;2:116-124.

5. Elder NC, Vonder Meulen M, Cassedy A. The identification of medical errors by family physicians during outpatient visits. Ann Fam Med. 2004;2:125-129.

6. Gramling R, Nash J, Siren K, Eaton C, Culpepper L. Family physician self-efficacy with screening for inherited cancer risk. Ann Fam Med. 2004;2:130-132.

7. Mainous AG III, Gill JM, Carek PJ. Elevated serum transferrin saturation and mortality. Ann Fam Med. 2004;2:133-138.

8. Mainous AG III, Wells B, Carek PJ, Gill JM, Geesey ME. The mortality risk of elevated serum transferren saturation and consumption of dietary iron. Ann Fam Med. 2004;2:139-144.

9. Keeley RD, Birchard A, Dickinson P, et al. Parental attitudes about a pregnancy predict birth weight in a low-income population. Ann Fam Med. 2004;2:145-149.

10. Gask L. Powerlessness, control, and complexity: the experience of family physicians in a group model HMO. Ann Fam Med. 2004;2: $150-155$.

11. US Preventive Services Task Force. Screening for family and intimate partner violence: recommendation statement. Ann Fam Med. 2004;2: 156-160.

12. Nelson HD, Nygren P, Klein J. Screening children for family violence: a review of the evidence for the US Preventive Services Task Force. Ann Fam Med. 2004;2:161-169.

13. Park EW, Tudiver F, Schultz JK, Campbell T. Does enhancing partner support and interaction improve smoking cessation? A meta-analysis. Ann Fam Med. 2004;2:170-174.

14. Rosenblatt RA. Getting the news. Ann Fam Med. 2004;2:175-176.

15. Future of Family Medicine Project Leadership Committee. The future of family medicine: a collaborative project of the family medicine community. Ann Fam Med. 2004;2(Suppl 1):S3-S32.

16. Future of Family Medicine Project Leadership Committee. The future of family medicine: a collaborative project of the family medicine community [online]. Ann Fam Med. 2004;2(Suppl 1). Available at: http://www.annfammed.org/cgi/content/full/2/suppl_1/S3.

\title{
EDITORIAL
}

\section{Motherhood, Apple Pie, and COPC}

\author{
Robert L. Williams, MD, MPH
}

Department of Family and Community Medicine, University of New Mexico School of Medicine, Albuquerque, NM

Ann Fam Med 2004;2:100-102. DOI: 10.1370/afm.70.

Conflicts of interest: none reported

\section{CORRESPONDING AUTHOR:}

Robert Williams, MD, MPH

Department of Family and Community Medicine

2400 Tucker Ave. NE

Albuquerque, NM 87131

rlwilliams@salud.unm.edu
T The dramatic progress of the Human Genome Project during the last decade has highlighted the strength of the reductionist approach to biomedical science. In essence, by reducing human disease to a matter of mistaken DNA and the resulting amino acids, we may be able to greatly increase our means to prevent, diagnose, or treat that disease.

Even as we celebrate the successes throughout 